\title{
Critical Current of Superconducting Rutherford Cable in High Magnetic Fields with Transverse Pressure
}

\author{
Daniel R. Dietderich and Ronald M. Scanlan, \\ Lawrence Berkeley National Laboratory, Berkeley, CA 94720 \\ Robert P. Walsh and John R. Miller \\ National High Magnetic Field Laboratory, Tallahassee, FL 32706
}

\begin{abstract}
For high energy physics applications superconducting cables are subjected to large stresses and high magnetic fields during service. It is essential to know how these cables perform in these operating conditions. A loading fixture capable of applying loads of up to $700 \mathrm{kN}$ has been developed by NHMFL for LBNL. This fixture permits uniform loading of straight cables over a $122 \mathrm{~mm}$ length in a split-pair solenoid in fields up to $12 \mathrm{~T}$ at $4.2 \mathrm{~K}$. The first results from this system for Rutherford cables of internal-tin and modified jelly roll strand of $\mathrm{Nb}_{3} \mathrm{Sn}$ produced by IGC and TWC showed that little permanent degradation occurs up to $210 \mathrm{MPa}$. However, the cable made from internal-tin strand showed a $40 \%$ reduction in $I_{c}$ at $11 \mathrm{~T}$ and $210 \mathrm{MPa}$ while a cable made from modified jelly roll material showed only a $15 \%$ reduction in $I_{c}$ at $11 \mathrm{~T}$ and 185 MPa.
\end{abstract}

\section{INTRODUCTION}

Large forces are produced when superconducting magnets are energized. Therefore, it is necessary to support the conductor to prevent large displacements that can strain the conductor beyond its elastic limit. These same forces also reduce the critical current of the conductor before the elastic limit is reached. To produce an optimum magnet design which best utilizes the superconductor material and maximizes the field the critical current variation with pressure is required.

For a cosine $\Theta$ magnet design large pressures are produced at the mid-plane of the magnet on the large face of the Rutherford cable. The magnets (i.e. common coil) presently being designed and built in the Superconducting Magnet Group (SMG) of Lawrence Berkeley National Laboratory such that the cable will be bi-axially loaded on both the face and the edge with the edge loading being about twice that applied to the face. Therefore information for loading in both orientations is required.

The results presented here are the first measurements performed at the National High Magnetic Field Laboratory (NHMFL) in a system designed for the SMG. These tests were performed on cable designed for and used in the inner coils of the world record dipole magnet D20 [1].

Manuscript received September 14, 1998.

This work was supported by the Director, Office of Energy Research, Office of High Energy and Nuclear Physics, High Energy Physics Division, U. S. Department of Energy, under Contract No. DE-AC03-6SF00098.
These cables were fabricated in our Group from modified jelly roll wire produced by Teledyne Wah Chang (TWC) and from internal tin wire manufactured by Intermagnetics General Corporation (IGC).

The results for both cables showed that very little if any permanent degradation occurred for transverse loads up to 185 to $210 \mathrm{MPa}$. However, the critical current of the cable with IGC strand was reduced by $40 \%$ with a transverse pressure of $210 \mathrm{MPa}$ at $11 \mathrm{~T}$. The $\mathrm{I}_{\mathrm{c}}$ of the cable with TWC strand was only reduced by $15 \%$ at $11 \mathrm{~T}$ and $185 \mathrm{MPa}$. The behavior of both cables with loading was also different. The TWC strand showed a quadratic behavior with increasing pressure while the IGC strand showed a linear behavior.

These results have important ramifications for high field magnet designs beyond the $13.5 \mathrm{~T}$ of D20. Not only must the strain level be controlled to prevent irreversible damage at these higher fields but the reduction in critical current due to the lower $\mathrm{T}_{\mathrm{c}}$ and $\mathrm{B}_{\mathrm{c} 2}$ with high pressure must be controlled.

\section{MATERIALS AND TEST SYSTEM}

\section{A. Strand and Cable Characteristics}

Two strands made by two manufacturers were used in the Rutherford cables of this study. Cable 523 wás made from IGC strand while cable 522 was made from TWC strand. Each cable was rectangular and contained 37 strands. The cabling parameters are listed in Table I.

Strand specifications are given in Table II. The two strands had very different internal geometries. The TWC strand had more $\mathrm{Cu}$ stabilizer and each of its 120 sub-elements had its own diffusion barrier. (Fig. 1(a)) The IGC strand had less $\mathrm{Cu}$ stabilizer and a diffusion barrier around all of its 19 subelements (Fig. 1(b)).

Both cables were heat treated at the same time and received the following schedule: $210^{\circ} \mathrm{C}$ for $121 \mathrm{~h}, 340^{\circ} \mathrm{C}$ for $60 \mathrm{~h}$, and $660^{\circ} \mathrm{C}$ for $259 \mathrm{~h}$. For heat treatment the samples were sealed in a stainless steel retort that was continuously purged with flowing argon.

The data has not been corrected for self-field but due to the bifilar nature of the test arrangement the correction should be small. 
TABLE I

CABLE ChaRACteristics

\begin{tabular}{cccccc}
\hline $\begin{array}{c}\text { Cable } \\
\text { No. }\end{array}$ & MFG. & $\begin{array}{c}\text { Cable } \\
\text { Comp(\%) }\end{array}$ & $\begin{array}{c}\text { Thickness } \\
(\mathrm{mm})\end{array}$ & $\begin{array}{c}\text { Width } \\
(\mathrm{mm})\end{array}$ & $\begin{array}{c}\text { Cable Pitch } \\
\text { Length } \\
(\mathrm{mm})\end{array}$ \\
\hline 522 & TWC & 84.1 & 1.356 & 14.45 & 90 \\
523 & IGC & 84.1 & 1.369 & 14.45 & 90 \\
\hline
\end{tabular}

TABLE II

STRAND CHARACTERISTICS

\begin{tabular}{ccccc}
\hline $\begin{array}{c}\text { Cable } \\
\text { No. }\end{array}$ & $\begin{array}{c}\text { Strand Dia. } \\
(\mathrm{mm})\end{array}$ & $\begin{array}{c}\text { Cu to SC } \\
\text { fraction }\end{array}$ & $\begin{array}{c}\text { Sub-elements } \\
\text { Dia. }(\mu \mathrm{m})\end{array}$ & $\begin{array}{c}\text { No. Sub- } \\
\text { elements }\end{array}$ \\
\hline 522 & 0.75 & 1.08 & $50-70$ & 122 \\
523 & 0.75 & 0.67 & $140-190$ & 19 \\
\hline
\end{tabular}
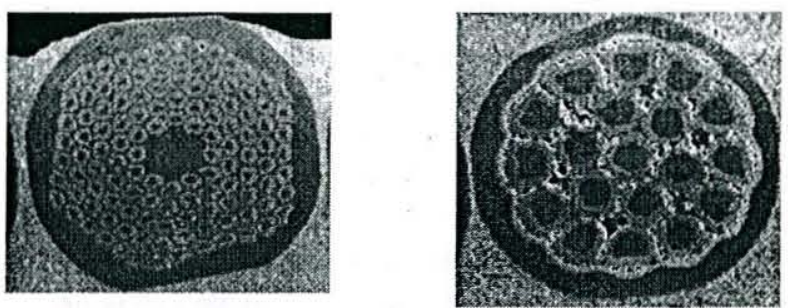

Fig. 1. (a) TWC strand of cable 522 and (b) IGC strand of cable 523 after heat treatment.

\section{B. Cable Assembly}

The cable stack in the loading region consisted of four cables, two active cables which carry the current and two dummies. The active cables carry the current in opposite directions and the dummy cables on either side of the active cables simulate a magnet environment and also reduce any stress concentration that may arise from non-uniform loading. For heat treatment the cable stack is placed into reaction tooling made of 304 stainless steel. The dimensions of the tooling and the shimming schedule were designed to confine as well as to compress the cable to its theoretical thickness, i.e. cable thickness plus insulation thickness. A sleeve of S-2 glass insulated each cable. The wall thickness of the sleeve was $0.125 \mathrm{~mm}$. An additional sheet of S-2 glass with a thickness of $0.25 \mathrm{~mm}$ was wrapped around the cable stack without an overlap before putting it into the reaction tooling.

Three solder box connections were made to each sample. At the top of each sample the active cables are displaced from each other by a hard way bend forming a wishbone. To make connections to the sample the active cables are sandwiched between two $\mathrm{Nb}$ - $\mathrm{Ti}$ cables which extend beyond the sample assembly. The Nb-Ti and active cable interleaved with sheets of eutectic $\mathrm{Pb}$-Sn solder. A U-shaped copper box with a copper lid holds the stack together while it is heated. Pressure applied to the lid during heating compresses the stack when the solder melts. This technique produces a robust joint with low resistivity ( $<1 \mathrm{n} \Omega-\mathrm{cm}$ ). The same solder box technique was used at the bottom of the sample to join the two active cables forming the current return.

Voltage taps were attached to the sample at four locations. Prior to heat treatment 304 stainless steel strips $0.025 \mathrm{~mm}$ thick were wrapped around the cable at the voltage tap locations. These stainless steel taps were in contact with all of the strands of the cable. After heat treatment twisted pair leads are soldered to these stainless steel tabs. Two sets of taps were attached to the active cables between the $122 \mathrm{~mm}$ loading section, one on the upper cable and the other on the lower cable. These taps were $170 \mathrm{~mm}$ apart. The third pair were attached to the active cables just above the lower solder joint so that its resistivity can be monitored. The fourth pair were attached to the active cables at the two lead solder boxes so that the total voltage of the sample could be monitored.

After all of the solder connections to each cable have been made the sample is assembled in test tooling and potted. During assembly the sample is shimmed to the same theoretical thickness that was used for the heat treatment. The sample and the 304 stainless test tooling are then vacuum impregnated in a vertical orientation with Composite Technology Development 101 (CTD-101) epoxy producing a rugged test assembly.

The test tooling had a specially designed cover plate to permit uniform loading of the cable by the piston. Electrical discharge machine wire cuts along the plate produced a beam whose ends were attached and whose width matched that of the cable such that when loaded it deflects into the sample uniformly regardless of piston alignment.

\section{Magnet and Loading System}

The NHMFL has a split pair solenoid magnet with the solenoid axis in the horizontal orientation [2]. The magnet was manufactured by Oxford Instruments and can produce a field of $13 \mathrm{~T}$. This permits cables to be tested with the magnetic field perpendicular to the current in the cables. Samples are inserted into a radial access port, $30 \mathrm{~mm}$ by 70 $\mathrm{mm}$, which is perpendicular to the solenoid axis. A schematic of the sample assembly in the magnet is shown in Fig. 2. The inside diameter of the solenoid is $150 \mathrm{~mm}$. The loading assembly was designed to fit into this space.

A schematic of the loading assembly with piston, bellows, and housing are shown in Fig. 3. All of the components are made from 304L stainless steel. The radial access port of the piston is reduced to $25 \mathrm{~mm}$ by $65 \mathrm{~mm}$. This defined the maximum sample size to about $24.5 \mathrm{~mm}$ by $64 \mathrm{~mm}$. The bellows and piston assembly were designed for $\mathrm{He}$ gas pressures up to $10 \mathrm{MPa}$ (1,500 psi), which is just below the solidification of liquid helium at $4 \mathrm{~K}$. The reduction in area between the ends of the piston produces a 6 fold increase in pressure. The further reduction in area of the beam in the cover plate permits pressures of $380 \mathrm{MPa}$ to be attained. 


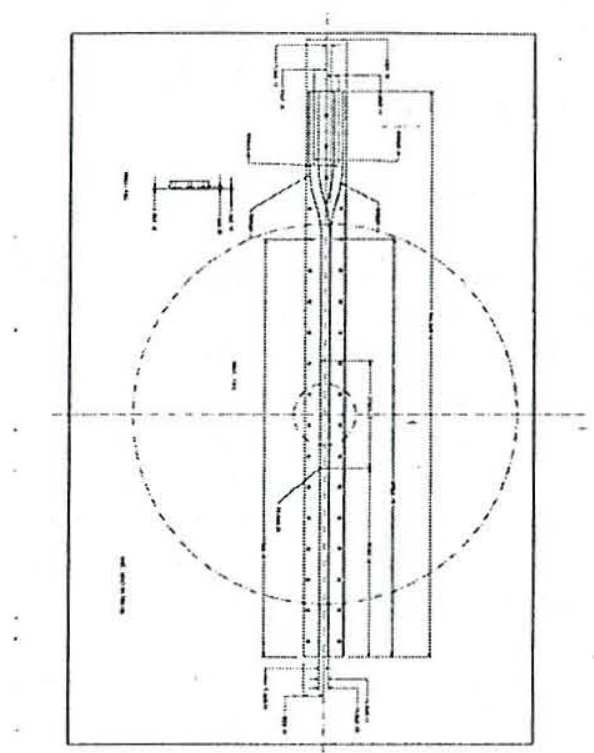

Fig. 2. Schematic of the sample holder superimposed on the magnet. The bore and outside diameter of the magnet are shown as dotted lines in the drawing. The magnet bore is $150 \mathrm{~mm}$. The sample is shown in the testing orientation.

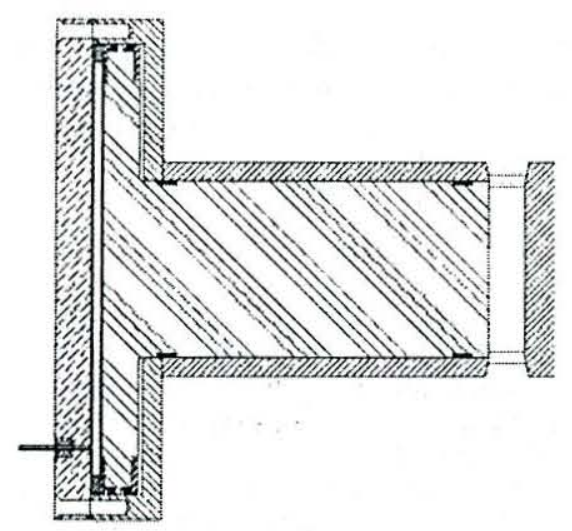

Fig. 3. Bellows, piston, and anvil assembly that is inserted into the bore of the slip pair magnets. The outside diameter of the piston and anvil housing is a little less that the magnet bore of $150 \mathrm{~mm}$.

\section{RESULTS AND DISCUSSION}

The variation of $I_{c}$ with transverse loading of cable 523 is shown in Fig. 4. All of the $I_{c}$ data for this cable was obtained from I-V curves with a quench behavior. After several training quenches, about 15 , a critical current of $12.5 \mathrm{kA}$ is attained. The critical current of the cable was then measured at loads of $50 \mathrm{MPa}$ and $100 \mathrm{MPa}$. The critical current was reduced to about $10 \mathrm{kA}$. After unloading the critical current was once again measured and it was $12.8 \mathrm{kA}$. The critical current increased slightly with the loading and unloading cycle.

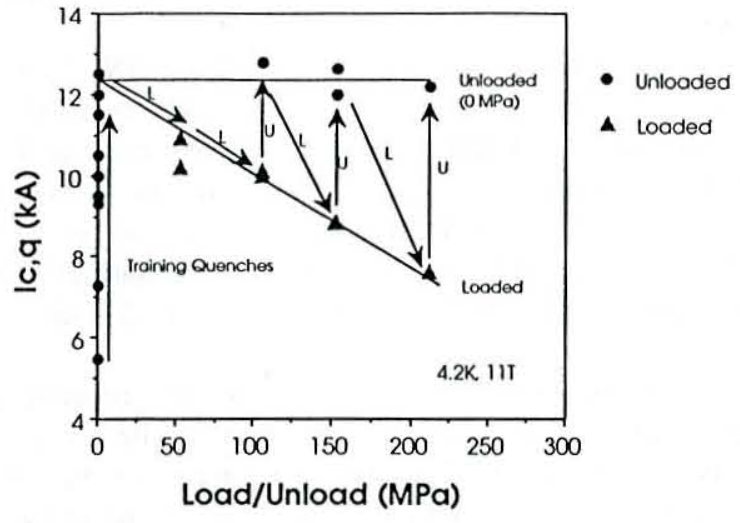

Fig. 4. Critical current (quench) variation with pressure of $\mathrm{Nb}_{3} \mathrm{Sn}$ cable 523 used for dipole magnet D20 of LBNL. Cable 523 has 37 strands of internal tin conductor produced by IGC.

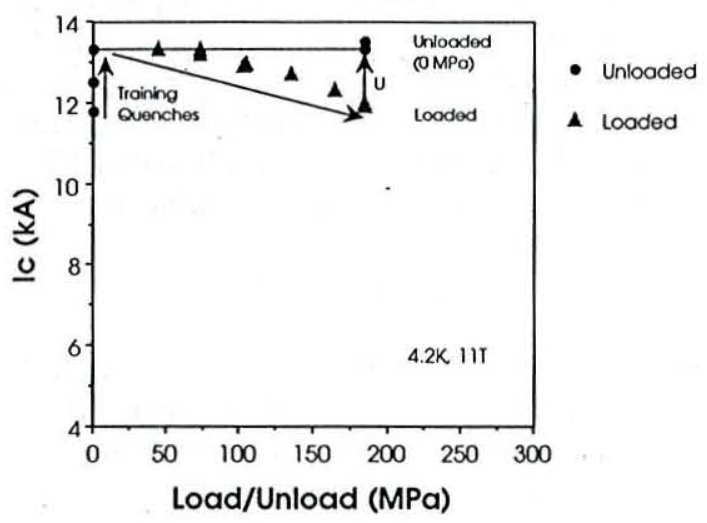

Fig. 5. Critical current variation with pressure of cable 522 used in D20 of LBNL. Cable 523 has 37 strands of modified jelly roll conductor produced by TWC.

The cable was then put through the following loading and unloading sequence: $150 \mathrm{MPa}$, unloaded, $210 \mathrm{MPa}$, and unloaded. The critical current was measured at each pressurization step and then unloaded to check for any permanent degradation of the cable. The permanent degradation was about $4 \%$ after loading to $210 \mathrm{MPa}$ if the $\mathrm{I}_{\mathrm{c}}$ of the unloaded virgin cable is $12.5 \mathrm{kA}$.

The variation in $\mathrm{I}_{c}$ with transverse loading of cable 522 can be seen in Fig. 5. This cable achieved a short sample $I_{c}$ of $13.5 \mathrm{kA}$ after only 3 quenches. This behavior is very different that of cable 523. All of the I-V curves had a smooth transition permitting easy determination of $\mathrm{I}_{\mathrm{c}}$ using a $10^{-12} \Omega$ $\mathrm{cm}$ criteria. However, the cable short sample is about $10 \%$ below what one would expect from the strand $I_{c}$ of $405 \mathrm{~A}$. From this strand $I_{c}$ one would calculate a cable $I_{c}$ of $15.0 \mathrm{kA}$. At this time the origin of the lower cable $I_{c}$ is not known but it is believed to be associated with strand damage from cabling. However, the cable showed no irreversible damage for 
stresses up to $185 \mathrm{MPa}$. Past work has shown that cabling damage of strand would show irreversible $I_{c}$ degradation for low stresses [3].

Some previous cable measurements on TWC conductor have shown it to be more sensitive to transverse loading. At first one may think that there is an inconsistency in the cable behavior but a direct comparison is difficult. This is due to significant difference in internal structure of the strand in different work and most of the earlier work was performed on keystoned cable with large compactions at the narrow edge $[3,4]$.

The internal structure of each strand after reaction can be seen in Fig. 1. There are a few features to be noticed about the two wires of Figs. 1(a) and 1(b). One is the different subelement geometry and $\mathrm{Cu}$ distribution due to the different manufacturing methods. Another is the wire produced by the internal-tin process has much more porosity than that produced by the modified jelly roll process. The authors do not want to get into a discussion of the origin of this porosity but just want to note the differences between the two strands.

Prior work suggests a functional form for the $I_{c}$ versus pressure behavior for $\mathrm{Nb}_{3} \mathrm{Sn}$ [4]. Briefly summarizing the approach, by using the empirical relations for $\mathrm{J}_{c}(\mathrm{~T})$ and $\mathrm{J}_{\mathrm{c}}(\mathrm{B})$ developed by [4] and using expressions $\mathrm{B}_{\mathrm{c} 2}(\sigma)$ and $\mathrm{T}_{\mathrm{c}}$ one can express the change of critical current with pressure in the form:

$$
\mathrm{I}_{\mathrm{c}}=\mathrm{I}_{\mathrm{c} 0}+\mathrm{I}_{\mathrm{cl}} \mathrm{P}+\mathrm{I}_{\mathrm{c} 2} \mathrm{P}^{2} \text {. }
$$

Where $\mathrm{P}$ is the traverse pressure on the cable and $\mathrm{I}_{\mathrm{c} 0}, \mathrm{I}_{\mathrm{cl}}$ and $\mathrm{I}_{\mathrm{c} 2}$ are coefficients determined by fitting the data or theory. By using either relations by Ekin [7] for $\mathrm{B}_{\mathrm{c} 2}(\varepsilon)$ and $\mathrm{T}_{c}(\varepsilon)$ with $\varepsilon$ replaced by $(\sigma / E)$ or ones with a linear form for $\mathrm{B}_{\mathrm{c} 2}(\mathrm{P})$ and $\mathrm{T}_{\mathrm{c}}(\mathrm{P})$ by saving only terms in to second order expression (1) is obtained. By substituting values $\mathrm{T}_{\mathrm{c} 0}=18.3$, $\mathrm{Bc} 2=25 \mathrm{~T}, \mathrm{dT}_{\mathrm{c}} / \mathrm{dP}=-0.18 \mathrm{~K} / \mathrm{Gpa}$, and $\mathrm{dB}_{\mathrm{c} 2} / \mathrm{dP}=-1.2 \mathrm{~T} / \mathrm{G}$ from [8] one can obtain theoretical values for the coefficients. Different values for these coefficients are obtained depending on the empirical expressions used to calculate them and thus give (1) either a linear or quadratic character. Ekin's relations $\mathrm{B}_{\mathrm{c} 2}$ and $\mathrm{T}_{\mathrm{c}}$ give a linear form to (1) while linear expressions for $\mathrm{B}_{\mathrm{c} 2}$ and $\mathrm{T}_{\mathrm{c}}$ give a quadratic form.

For the cables studied here 523 would have an $\mathrm{I}_{\mathrm{cl}}$ much greater than $I_{c 2}$ while 523 would have $I_{c 2}$ much greater than $I_{c 1}$. Prior work to explain the behavior in $I_{c}$ of cables with transverse pressure has shown that either behavior is possible

TABLE III.

\begin{tabular}{cccccc}
\hline $\begin{array}{c}\text { Cable } \\
\text { No. }\end{array}$ & Fit & $\begin{array}{c}\mathrm{I}_{\mathrm{c} 0} \\
(\mathrm{kA})\end{array}$ & $\begin{array}{c}\mathrm{I}_{\mathrm{cl}} \\
(\mathrm{kA} / \mathrm{MPa})\end{array}$ & $\begin{array}{c}\mathrm{I}_{\mathrm{c} 2} \\
\left(\mathrm{kA} / \mathrm{MPa}^{2}\right)\end{array}$ & $\mathrm{R}^{2}$ \\
\hline 522 & Quadratic & 13.30 & $2.37 \times 10^{-3}$ & $-5.20 \times 10^{-5}$ & 0.992 \\
522 & Linear & 13.57 & $-7.57 \times 10^{-3}$ & $\ldots-\cdots-\cdots-$. & 0.871 \\
523 & Quadratic & 12.13 & $-1.96 \times 10^{-2}$ & $-9.05 \times 10^{-6}$ & 0.977 \\
523 & Linear & 12.15 & $-2.14 \times 10^{-2}$ & $\ldots \ldots \ldots--$ & 0.977 \\
\hline
\end{tabular}

ASC'98 Palm Desert

September 14-18, 1998

in $\mathrm{Nb}_{3} \mathrm{Sn}$ cable. If one fits the $\mathrm{I}_{\mathrm{c}}$ versus loading data for both cables the coefficients for (1) can be obtained and are given in Table III. This shows that the data for 522 is almost quadratic while that of 523 is almost linear.

\section{CONCLUSIONS}

The results presented here show that two cables one made with IGC strand and the other with TWC strand have very different $I_{c}$ versus pressure behavior. The critical current of cable 523 made by the internal-tin process (IGC) shows a linear decrease with pressure while the critical current of cable 522 made by the modified jelly roll process is parabolic. The internal tin strand also seems be more sensitive to pressure with a decrease of about $40 \%$ in $\mathrm{I}_{c}$ for loads of $210 \mathrm{MPa}$. The $I_{c}$ of the modified jelly roll strand (TWC) only decrease by $11 \%$ at a pressure of $185 \mathrm{MPa}$. It may be premature to made strong statements as to the origin of these differences in behavior but the different internal structure of the two strands suggest that the high porosity of internal tin strand is detrimental.

\section{ACKNOWLEDGMENT}

The authors would like to thank the technical staff of the NHMFL for all of their assistance during experimental set up and testing. DRD would like to thank Andy Powell and Peter Murphy of NHMFL's electronic support group for equipment fabrication and system diagnostics.

\section{REFERENCES}

[1] A. D. McInturff, R. Benjegerdes, P. Bish, S. Caspi, K. Chow, D. Dell'Orco, D. R. Dietderich, R. Hannaford, W. Harnden, H. Higley, A. Lietzke, L. Morrison, M. Morrison, R. Scanlan, J. Smithwick, C. Taylor, and J. van Oort, "Test results for a high field (13T) $\mathrm{Nb}_{3} \mathrm{Sn}$ dipole," Proc. Particle Accel. Conf., May 12-16, Vancouver, B.C. Canada., in press.

[2] L.T. Summers, R. P. Walsh, and J. R. Miller, "A facility for the characterization of the critical current of superconductors as a function of strain and magnetic field," IEEE Trans. Appl. Super., vol. 5 pp. 1896-1899, June 1995.

[3] J. M. van Oort, R. M. Scanlan, H.W. Weijers, S. Wessel, H.H.J. ten Kate, "The reduction of the critical current in $\mathrm{Nb}_{3} \mathrm{Sn}$ cables under transverse loads," IEEE Trans. Appl. Super., vol. 3 pp. 559-562, March 1993.

[4] J. M. van Oort, Ph. D. Thesis in progress, University of Twente, Netherlands.

[5]. H.H.J. ten Kate, H.W. Weijers, J.M. van Oort, "Critical current degradation in $\mathrm{Nb}_{3} \mathrm{Sn}$ cables under transverse pressure," IEEE Trans. Appl. Super., vol. 3 pp. 1334-1337, March 1993.

[6] D.P. Hampshire, H. Jones, and E.W.J. Mitchell, "An in-depth characterization of (Nb,Ta)3Sn filamentary superconductor,' IEEE Trans. Mag., Vol. MAG-21, pp. 289-292, March 1985

[7] J.W. Ekin, "Strain scaling law for flux pinning in practical superconductors. Partl: Basic relationships and application to $\mathrm{Nb} 3 \mathrm{Sn}$ conductors," Cryogenics, vol. 20, p 611, 1980.

[8] B. ten Haken, "Strain effects on the critical properties of high-field superconductors," $\mathrm{Ph}$. D. Thesis, University of Twente, Netherlands. September 1994. 